\title{
Preparation of 4-benzylsulfanyl[1,2,3,5]dithiadiazol-1-ylium chlorides: potential precursors to meso-ionic 1,2,3,5- dithiadiazolium-4-thiolate
}

\author{
Thomas Gelbrich, ${ }^{a}$ Mark Humphries, ${ }^{b}$ Michael B. Hursthouse, ${ }^{a}$ \\ and Christopher A. Ramsden*b \\ ${ }^{a}$ Department of Chemistry, University of Southampton, Highfield, Southampton SO17 1BJ, UK, \\ and ${ }^{b}$ Lennard-Jones Laboratories, School of Chemistry and Physics, Keele University, Keele, \\ Staffordshire, UK ST5 5BG \\ E-mail: c.a.ramsden@chem.keele.ac.uk
}

Dedicated to Professor Charles W. Rees on the occasion of his $75^{\text {th }}$ birthday

(received 05 Jul 02; accepted 03 Oct 02; published on the web 11 Oct 02)

\begin{abstract}
Treatment of $S$-benzyl-iso-thiuronium chlorides with sulfur monochloride $\left(\mathrm{S}_{2} \mathrm{Cl}_{2}\right)$ gives the corresponding $S$-benzyl-1,2,3,5-thiadiazolium chlorides 2 as deep red crystalline compounds. The structure of the $p$-chlorobenzyl derivative 2a has been confirmed by X-ray crystallography. Attempts to generate the unknown type-B meso-ionic compound 1,2,3,5-dithiadiazolium-4thiolate 1 by reaction of these salts with nucleophiles were unsuccessful. AM1 semi-empirical molecular orbital calculations suggest that, although the meso-ionic structure corresponds to a local energy minimum, acyclic valence tautomers could equilibrate in solution and lead to further reaction.
\end{abstract}

Keywords: Meso-ionic, 1,2,3,5-dithiadiazolium salts, sulfur monochloride, $S$-benzyl-isothiuronium chlorides, AM1 calculations

\section{Introduction}

We have a long-standing interest in the bonding and reactions of dipolar ${ }^{1}$ and hypervalent ${ }^{2}$ molecules. In this paper we describe studies directed towards the preparation of the unknown type-B meso-ionic heterocycle 1,2,3,5-dithiadiazolium-4-thiolate 1. Meso-ionic compounds are five-membered heterocyclic conjugated betaines. ${ }^{3}$ They can only be represented by dipolar or hypervalent structures and are sub-divided into two distinct families (type-A and type-B) which have quite different general properties. Type-A systems, represented by $N$-phenyl sydnone 3 , are cyclic 1,3-dipoles e.g. structure 4. Type-B meso-ionic compounds are represented by 
dehydrodithizone 5: these systems are more closely related to 1,4-dipoles and much of their chemistry can be rationalized by equilibration with a valence tautomer e.g. 6. Because of their participation in useful 1,3-dipolar cycloaddition reactions, the chemistry of type-A meso-ionic compounds has been extensively studied. The type-B compounds are less well known.

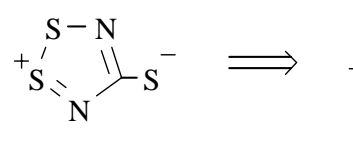

1

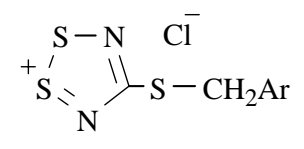

2
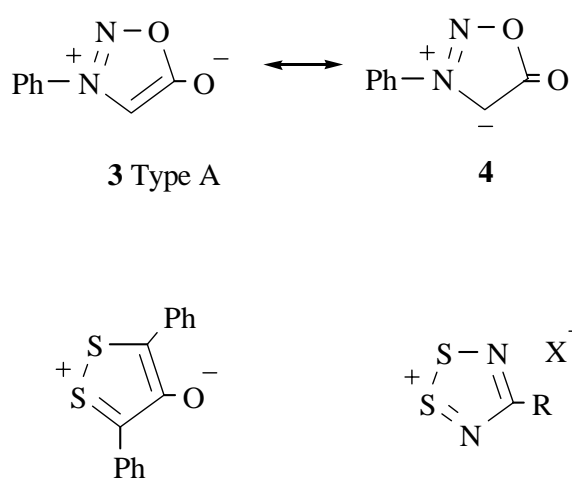

7

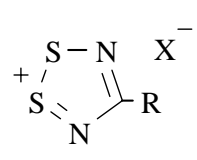

8

Both dehydrodithizone 5 and the 1,2-dithiolium-4-olate 7 are stable crystalline compounds whose structures have been confirmed by X-ray crystallography. ${ }^{4,5,6}$ Since the molecule $\mathbf{1}$ is essentially a hybrid of structural fragments found in the molecules $\mathbf{5}$ and $\mathbf{7}$, and other well known type-B meso-ionic molecules, it is not unreasonable to suppose that 1,2,3,5-dithiadiazolium-4thiolate $\mathbf{1}$, if formed, might also be stable and crystalline. We now report the preparation of the novel precursors $\mathbf{2}$ and unsuccessful attempts to prepare compound $\mathbf{1}$ by reaction with nucleophiles.

\section{Results and Discussion}

Our approach to compound $\mathbf{1}$ was based on the assumption that treatment of an $S$-benzyl[1,2,3,5]dithiadiazol-4-ylium salt 2 with a suitable nucleophile would result in an $S_{N} 2$ displacement and liberation of the meso-ionic heterocycle $\mathbf{1}$. A number of dithiadiazolium salts $\mathbf{8}$ are well characterised including 4-aryl, ${ }^{7,8}$ 4-heteroaryl, ${ }^{8}$ 4-trichloromethyl ${ }^{9}$ and 4-amino derivatives ${ }^{10}$ (8; $\mathrm{R}=\mathrm{Ar}, \mathrm{Cl}_{3} \mathrm{C}, \mathrm{NR}_{2}$ ). At the outset of this work 4-S-substituted 1,2,3,5dithiadiazolium salts were unknown but subsequently Tschöpe and co-workers ${ }^{11}$ described the characterisation of six $S$-aryl derivatives $(\mathbf{8}$; $\mathrm{R}=\mathrm{SAr}, \mathrm{X}=\mathrm{Cl})$ and, in a later paper, ${ }^{12}$ the preparation and crystal structure of the $4-S$-(o,p-dinitrobenzyl) chloride $2 \mathrm{f}$. As far as we are aware this is the only $S$-benzyl derivative (i.e. 8, $\mathrm{R}=\mathrm{SCH}_{2} \mathrm{Ar}$ ) that has been reported. We now describe the preparation and characterisation of the $S$-benzyl chlorides 2a-d (Scheme 1) by reaction of the well-known $S$-benzyl-iso-thiuronium chlorides 9 with sulfur monochloride $\left(\mathrm{S}_{2} \mathrm{Cl}_{2}\right)$. 
The $S$-benzyl-iso-thiuronium salts $\mathbf{9}$ were prepared by reaction of the corresponding benzyl chloride with thiourea in hot ethanol. Treatment of a hot toluene solution of the salt 9a with two equivalents of sulfur monochloride under a nitrogen atmosphere gave a red solution which upon cooling deposited bright red crystals of the chloride 2a. Subsequently it was found that the solvent is unnecessary and good yields are obtained by heating the reactants together. In preliminary experiments we also added four equivalents of DBU to facilitate elimination of $\mathrm{HCl}$ but we found this to be unnecessary. The structure $\mathbf{2 a}$ was fully supported by elemental analysis and spectral data. The ${ }^{1} \mathrm{H}$ NMR spectrum is limited to a benzyl singlet at $\delta 4.67$ and phenyl protons in the range $\delta$ 7.2-7.5. Mass spectrometry showed a molecular ion corresponding to the cation $(\mathrm{m} / \mathrm{z} 227)$. Originally we anticipated that the S-S bond in the dithiadiazolium ring would originate from the $\mathrm{S}_{2} \mathrm{Cl}_{2}$. However, based on the formation of similar products by reaction of amidines and guanidines with sulfur dichloride $\left(\mathrm{SCl}_{2}\right)$, we now believe that the formation of the product 2a probably takes place via the mechanism shown in Scheme 1.

Although reasonably stable under an inert atmosphere and at ambient temperature, the product 2a decomposes on heating or upon attempted recrystallisation from organic solvents. The product also slowly decomposes when left exposed to the atmosphere. In all cases the decomposition products were colourless and insoluble but attempts to characterise decomposition products of the unsubstituted derivative $\mathbf{2 a}$ were unsuccessful.

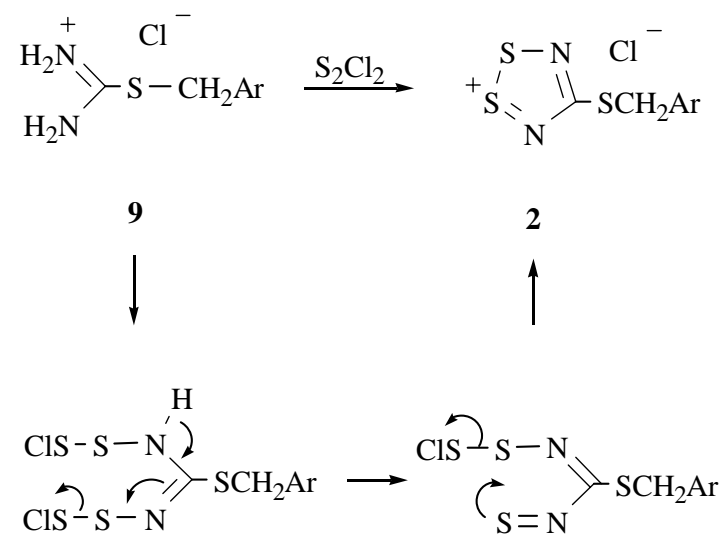

In structures $\mathbf{2}$ and $\mathbf{9}$ :
(a) $\mathrm{Ar}=\mathrm{Ph}$;
(b) $\mathrm{Ar}=p-\mathrm{ClC}_{6} \mathrm{H}_{4}$;
(c) $\mathrm{Ar}=p-\mathrm{CF}_{3} \mathrm{C}_{6} \mathrm{H}_{4}$;
(d) $\mathrm{Ar}=p-\mathrm{CH}_{3} \mathrm{C}_{6} \mathrm{H}_{4}$;
(e) $\mathrm{Ar}=p-\mathrm{CH}_{3} \mathrm{OC}_{6} \mathrm{H}_{4}$;
(f) $\mathrm{Ar}=o, p-\mathrm{diNO}_{2} \mathrm{C}_{6} \mathrm{H}_{3}$.

\section{Scheme 1}

Using a similar preparative procedure the substituted derivatives $\mathbf{2 b - e}$ were also prepared. Electron-withdrawing groups on the benzyl substituent considerably enhance the stability of the 
salts 2 and the $p$-Cl and $p$ - $\mathrm{CF}_{3}$ derivatives $\mathbf{2 b}, \mathbf{c}$ were considerably more stable and easier to handle than the parent compound $\mathbf{2 a}$. In contrast, the $p$-Me derivative has stability comparable to the phenyl derivative whereas the $p$ - $\mathrm{MeO}$ derivative was too unstable to characterise and was always obtained as a mixture.

The enhanced stability and ease of handling of the $p$-Cl derivative $\mathbf{2} \mathbf{b}$ enabled us to obtain crystals suitable for X-ray diffraction which confirmed the 1,2,3,5-dithiadiazolium structure 2. The molecular structure of compound $\mathbf{2 b}$ is shown in Figure 1.

The bond distances and angles of the chloride $\mathbf{2} \mathbf{b}$ are in agreement with those parameters observed for the structurally related 4-(o,p-dinitrobenzylthio)-1,2,3,5-dithiadiazolium chloride 2f. ${ }^{12}$ The conformation of each of these two structures can be characterised by a set of three torsion angles (Table 1). Two of these torsion angles remain essentially unchanged, whereas the "central" C(1)-S(3)-C(2)-C(3) torsion angle in structure $\mathbf{2 b}$ differs fundamentally from its counterpart in structure 2f. The shortest intermolecular $\mathrm{Cl}$...S distances $\mathrm{Cl}(2) \ldots \mathrm{S}(1)=2.901 \AA$ and $\mathrm{Cl}(2) \ldots \mathrm{S}(2)=2.894 \AA$ are significantly shorter than sum of van der Waals radii of $3.55 \AA$. Equally short $\mathrm{Cl}$...S contacts of similar geometry (2.792 and $2.930 \AA$ ) occur in the structure of 2f. $^{12}$

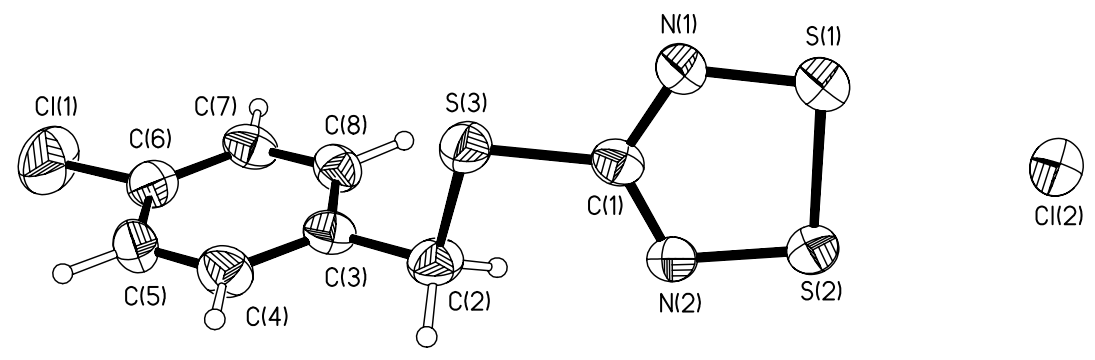

Figure 1. Structure of dithiadiazol-1-ylium chloride 2b showing 30\% probability displacement ellipsoids.

Table 1. Comparison between torsion angles in structure $\mathbf{2 b}$ and in 4-(2,4-dinitrobenzylthio)1,2,3,5-dithiadiazolium chloride $\mathbf{2} \mathbf{f}^{12}$

\begin{tabular}{ccc}
\hline & 2b & 2f \\
\hline $\mathrm{S}(3)-\mathrm{C}(2)-\mathrm{C}(3)-\mathrm{C}(8)$ & $86.7^{\circ}$ & $85.7^{\circ}$ \\
$\mathrm{C}(1)-\mathrm{S}(3)-\mathrm{C}(2)-\mathrm{C}(3)$ & $-155.8^{\circ}$ & $86.1^{\circ}$ \\
$\mathrm{N}(1)-\mathrm{C}(1)-\mathrm{S}(3)-\mathrm{S}(2)$ & $172.2^{\circ}$ & $179.9^{\circ}$ \\
\hline
\end{tabular}

Having prepared and fully characterised the $S$-benzyl salts 2a-e, we then investigated the reactions of the $p$-chloro derivative $\mathbf{2 b}$ with various nucleophiles in an attempt to generate the meso-ionic dithiadiazolium-4-thiolate $\mathbf{1}$. In "wet" solvents (DMF and THF) the salt $\mathbf{2 b}$ is unstable giving the salt $\mathbf{9 b}$ and sulfur. This hydrolysis is avoided using freshly dried and distilled DMF or THF in which compound $\mathbf{2 b}$ is both soluble and stable. The reaction of the salt $\mathbf{2} \mathbf{b}$ with various nucleophiles, including LiSMe, in dry solvent resulted in rapid decomposition with no identifiable products. At this stage it seemed appropriate to use a soft nucleophile that might 
favour attack of the benzyl carbon rather than the charged ring and in this context it occured to us to use thiourea as the nucleophile. Initial attempts were carried out using dry DMF as solvent but product recovery was difficult. When compound $\mathbf{2 b}$ was treated with thiourea in dry THF a colour change immediately occured and the expected $S$-benzylthiuronium salt $\mathbf{9 b}$ was indeed rapidly formed and could be isolated, together with crystalline sulfur, and fully characterised. The simplest rationalisation for the formation of the salt $\mathbf{9 b}$ is by the mechanism shown in Equation 1 which implies simultaneous formation of the desired product $\mathbf{1}$. However, all attempts to isolate or detect the meso-ionic product $\mathbf{1}$ were unsuccessful and we conclude that if compound $\mathbf{1}$ is formed under these conditions then it rapidly decomposes and is too unstable to be isolated. One possible mode of decomposition is by valence tautomerism to give the acyclic isomer $(\mathrm{S}=\mathrm{N})_{2} \mathrm{C}=\mathrm{S}$. We cannot eliminate the possibility that the thiourea attacks the dithiadiazolium ring and this may also result in formation of the salt $\mathbf{9 b}$.

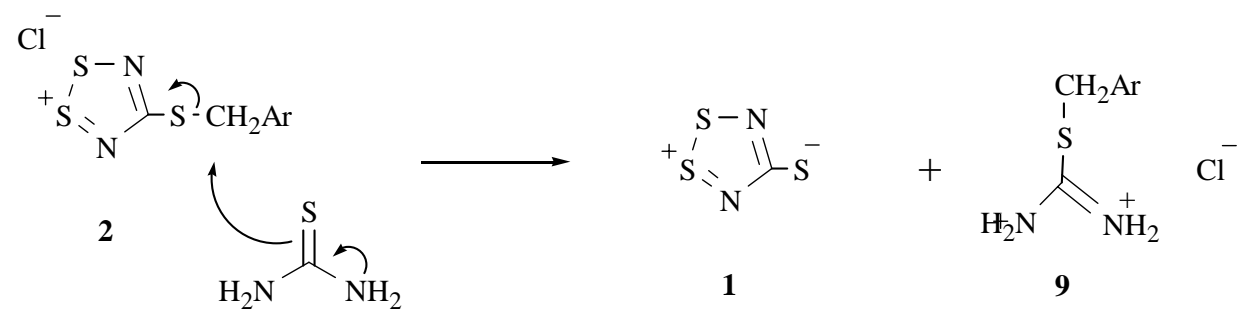

\section{Equation 1}

In order to further investigate the relative stability of the dithiadiazolium-4-thiolate structure 1, we have carried out AM1 molecular orbital calculations ${ }^{13}$ on the meso-ionic structure and three valence tautomers. The results for the meso-ionic ring $\mathbf{1}$ are shown in Table 2.

Table 2.The AM1 calculated properties of meso-ionic structure $\mathbf{1}$

\begin{tabular}{|c|c|c|c|}
\hline & $\begin{array}{l}2 \\
S^{\prime}- \\
S^{3} \\
N\end{array}$ & $\begin{array}{c}S_{\mathrm{N}} \\
S_{\mathbf{1 A}}-\overline{\mathrm{N}}\end{array}$ & $\begin{array}{l}{ }_{\mathrm{S}}^{+}=\mathrm{N} \\
\mathrm{S}_{\mathbf{\mathrm { N }}} \\
\mathbf{1 B}\end{array}$ \\
\hline & Charge & HOMO & LUMO \\
\hline Energy & & $-8.44 \mathrm{eV}$ & $-3.03 \mathrm{eV}$ \\
\hline N1 & -0.37 & +0.38 & 0.47 \\
\hline $\mathrm{S} 2+0.42$ & +0.42 & -0.28 & 0.53 \\
\hline $\mathrm{S} 3+0.42$ & +0.42 & -0.28 & +0.53 \\
\hline N4 & -0.37 & +0.38 & +0.47 \\
\hline C5 & -0.03 & -0.20 & 0.00 \\
\hline S6 & -0.07 & -0.74 & 0.00 \\
\hline
\end{tabular}

$\Delta \mathrm{H}_{\mathrm{f} \text { calcd }} 102.3 \mathrm{kcal} \mathrm{mol}^{-1}$

$\mu_{\text {calcd }}=6.86$ Debye 
Bond lengths $(\AA)$ : N1-S2, 1.52; S2-S3, 2.21; S3-N4, 1.52; N4-C5, 1.40; N1-C5, 1.40; C5-S6, 1.58 .

Structure 1 corresponds to a stable energy minimum which has the lowest heat of formation of all the isomers investigated. The calculated charge density is consistent with the molecule being a resonance hybrid of the canonical forms $\mathbf{1 A}$ and 1B (Table 2) with little charge on the exocyclic sulphur atom. The calculated CN (1.40 $\AA$ ) and CS (1.58 $\AA$ ) bond lengths are similar to those determined from an X-ray study ${ }^{4}$ of dehydrodithizone 5 [CN (1.36 $\AA$ ) and CS (1.69 $\left.\AA\right)$ ]. The calculated SS bond length $(2.21 \AA)$ is longer than that observed ${ }^{5,6}$ for compound 7 (2.01 $\AA$ ). Clearly the AM1 parameters were not optimised for sulphur-nitrogen rich molecules and the accuracy of the calculated geometries must be treated with some caution. Nevertheless, the calculated properties are consistent with structure $\mathbf{1}$ being a relatively stable entity.

Three other isomeric structures (10-12) corresponding to local energy minima were identified. Structures $\mathbf{1 0}$ and $\mathbf{1 1}$ are closely related acyclic valence tautomers having a mutual cis-trans relationship. Both of these structures are higher in energy than cyclic structure $\mathbf{1}$ but, bearing in mind solvent effects and the accuracy of calculations for NS systems, both of these structures are probably accessible in solution. The third structure $\mathbf{1 2}$ is more unusual and is calculated to be lower in energy than both $\mathbf{1 0}$ and 11. In structure $\mathbf{1 2}$ there is clearly a strong interaction between the nitrogen atoms ( $\mathrm{SS}_{\text {calc. }} 2.36 \AA$ ) with the CS bond calculated to be longer and more polar than in the meso-ionic structure $\mathbf{1}$. With a calculated heat of formation only ca 12 $\mathrm{kcal} \mathrm{mol}^{-1}$ higher than that of the five-membered ring $\mathbf{1}$, this species may well be accessible, or even the most stable, in solution and formation of this followed by further reactions could account for our failure to observe compound 1.

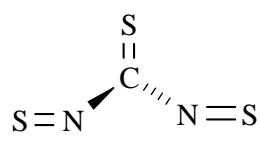

10

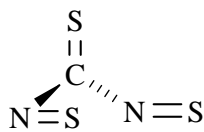

11

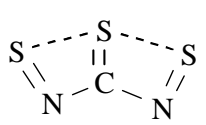

12

$\Delta \mathrm{H}_{\mathrm{f}} 114.2 \mathrm{kcal} \mathrm{mol}^{-1}$

$\Delta \mathrm{H}_{\mathrm{f}} 132.2 \mathrm{kcal} \mathrm{mol}^{-1}$

In conclusion, we have fully characterised novel 4-benzylsulfanyl[1,2,3,5]dithiadiazol-1ylium chlorides 2 . These salts are more stable if the phenyl ring carries an electron-withdrawing substituent, e.g. $p$-Cl or $p$ - $\mathrm{CF}_{3}$. Attempts to generate meso-ionic 1,2,3,5-dithiadiazolium-4thiolate $\mathbf{1}$ from the salt $\mathbf{2 b}$ were unsuccessful. Molecular orbital calculations suggest that structure 1 does correspond to a local energy minimum but that this structure may be in equilibrium with valence tautomers such as structures 10, 11 and 12.

\section{Experimental Section}


General Procedure. Melting points were determined using a Kofler hotplate apparatus and are uncorrected. Infrared spectra were recorded on a Philips FTIR PU 9802/25 spectrophotometer with only major absorbances being quoted. Unless otherwise stated IR spectra were measured using $\mathrm{KBr}$ pellets $(0.5 \mathrm{mg} / 300 \mathrm{mg} \mathrm{KBr}) .{ }^{1} \mathrm{H}$ NMR $(300 \mathrm{MHz})$ spectra were recorded at ambient temperatures using a Varian VXR-300 NMR spectrometer with either TMS or HMDS as an internal reference, and were run in deuterated chloroform solution unless otherwise stated. Chemical shifts are quoted in parts per million and the following abbreviations are used: $\mathrm{s}=$ singlet; $\mathrm{d}$ = doublet; $\mathrm{t}$ = triplet; $\mathrm{q}=$ quartet; $\mathrm{m}$ = multiplet; $\mathrm{br}=$ broad. Elemental analyses were determined using either a Perkin-Elmer 240 CHN Elemental Analyser or a Carlo Erba CHNSOEA 1108-Elemental Analyser. Separations by column chromatography were carried out using silica gel S (Riedel-deHaen) 0.002-0.063 mm or silica gel (Janssen Chimica) $0.035-0.07 \mathrm{~mm}$. All solvents were pre-distilled and dried appropriately prior to use. Concentration and evaporation refer to the removal of volatile materials under reduced pressure on a Büchi Rotovapor. Substances stated to be identical were so with respect to m.p.s, mixed m.p.s and IR spectra.

MO calculations were carried out using the AM1 semi-empirical method ${ }^{13}$ and energy was minimised with respect to all geometrical variables.

Crystal data. ${ }^{14}$ The intensity data were collected on a Nonius Kappa CCD area-detector diffractometer at the window of a rotating anode FR591 generator (Mo-K $\alpha$ radiation, $\lambda=$ $0.71073 \AA$ ). $\mathrm{T}=150 \mathrm{~K}$, formula $\mathrm{C}_{8} \mathrm{H}_{6} \mathrm{Cl}_{2} \mathrm{~N}_{2} \mathrm{~S}_{3}, M=297.23$, monoclinic space group $P 2_{1} / c, \mathrm{Z}=4$, $a=19.148(4) \AA, b=8.2470(16) \AA, c=7.5313(15) \AA, \beta=92.27(3)^{\circ}, U=1188.4(4) \AA^{3}, D_{c}=$ $1.661 \mathrm{Mg} / \mathrm{m}^{3}, \mu(\mathrm{Mo}-K \alpha)=1.039 \mathrm{~mm}^{-1}$. Orange plate, crystal size $0.10 \times 0.07 \times 0.03 \mathrm{~mm} .5659$ reflections measured, 2256 unique $\left(\mathrm{R}_{\mathrm{int}}=0.057\right)$. Final $R 1\left[\mathrm{~F}^{2}>2 \sigma\left(\mathrm{F}^{2}\right)\right]=0.049, w R 2\left[\mathrm{~F}^{2}>2 \sigma\left(\mathrm{F}^{2}\right)\right]$ $=0.069, R 1$ (all data $)=0.130, w R 2$ (all data $)=0.079$.

\section{Preparation of 4-benzylsulfanyl-[1,2,3,5]dithiadiazol-1-ylium chlorides 2}

4-Benzylsulfanyl-[1,2,3,5]dithiadiazol-1-ylium chloride (2a). Method A. A solution of sulfur monochloride $\left(\mathrm{S}_{2} \mathrm{Cl}_{2}\right)(4.0$ g., $30 \mathrm{mmol})$ in toluene $\left(20 \mathrm{~cm}^{3}\right)$ was added dropwise to a stirred suspension of $S$-benzyl-iso-thiuronium chloride 9 a $(3.0 \mathrm{~g}$., $15 \mathrm{mmol})$ in toluene $\left(50 \mathrm{~cm}^{3}\right)$ under an atmosphere of nitrogen. The resulting yellow mixture was then heated under reflux at $110{ }^{\circ} \mathrm{C}$ with stirring (2h) and then at room temperature (1h). The red mixture was allowed to stand (48 h) and the bright red crystals that formed were collected, recrystallised from $\mathrm{S}_{2} \mathrm{Cl}_{2}$, washed with toluene and after drying under vacuum identified as 4-benzylsulfanyl-[1,2,3,5]dithiadiazol-1ylium chloride 2a (1.8 g., 60\%), bright red plates, m.p. $155-160{ }^{\circ} \mathrm{C}$. (Found: C, 36.37; H, 2.52; N, 10.91; S, 36.70; $\mathrm{Cl}, 13.90 . \mathrm{C}_{8} \mathrm{H}_{7} \mathrm{~N}_{2} \mathrm{~S}_{3} \mathrm{Cl}$ requires C, 36.57; $\mathrm{H}, 2.67 ; \mathrm{N}, 10.67 ; \mathrm{S}, 36.57 ; \mathrm{Cl}$, $13.52 \%) ; \quad v_{\max }(\mathrm{KBr}) / \mathrm{cm}^{-1} 3028,1640,1528,1450,1314,1280,1240,1068,704 ; \delta_{\mathrm{H}}$ $\left(\mathrm{SOCl}_{2} / \mathrm{CDCl}_{3}\right) 4.67$ (s, 2H, SCH$)_{2}$ ) 7.2-7.5 (m, 5H, C ${ }_{6} H_{5}$ ); m/z (Found: $226.9793 \mathrm{M}^{+}{ }_{-} \mathrm{Cl}$ requires 226.9814), 91 (100\%), 64. 
Method B. A mixture of sulfur monochloride $\left(\mathrm{S}_{2} \mathrm{Cl}_{2}\right)\left(20 \mathrm{~cm}^{3}\right)$ and $S$-benzyl-iso-thiuronium chloride 9a (3.0 g., $15 \mathrm{mmol}$ ) was heated under reflux under an atmosphere of nitrogen. After cooling and standing (12 h), the bright red crystals were collected, recrystallised from $\mathrm{S}_{2} \mathrm{Cl}_{2}$ and shown to be identical to a sample of the chloride 2a prepared by Method A.

Using a similar procedure the following chlorides were prepared from the corresponding isothiuronium chloride: 4-(4'-chlorobenzyl)sulfanyl-[1,2,3,5]dithiadiazol-1-ylium chloride $2 \mathbf{b}$ (73\%), bright red needles, m.p. 154-160 ${ }^{\circ} \mathrm{C}$ (decomp. with loss of colour). (Found: C, 32.36; H, 1.96; N, 9.50. $\mathrm{C}_{8} \mathrm{H}_{6} \mathrm{~N}_{2} \mathrm{~S}_{3} \mathrm{Cl}_{2}$ requires C, 32.32; $\left.\mathrm{H}, 2.02 ; \mathrm{N}, 9.43 \%\right) ; v_{\max }(\mathrm{KBr}) / \mathrm{cm}^{-1} 3032,1644$, 1537, 1490, 1408, 1283, 1244, 1091, 1015, 876, 840, 743; $\delta_{\mathrm{H}}\left(\mathrm{SOCl}_{2} / \mathrm{CDCl}_{3}\right) 4.62$ (s, 2H, $\mathrm{SCH}_{2}$ ), 7.33 (d, $2 \mathrm{H}, J 8.4 \mathrm{~Hz}$, aromatic $\left.\mathrm{H}\right), 7.41$ (d, $2 \mathrm{H}, J 8.4 \mathrm{~Hz}$, aromatic $\left.\mathrm{H}\right) ; m / z\left({ }^{35} \mathrm{Cl}\right)$ (Found: $260.9380 \mathrm{M}^{\cdot+}-\mathrm{Cl}$ requires 260.9382), 125 (100\%), 89, 64. 4-(4'-trifluoromethylbenzyl)sulfanyl[1,2,3,5] dithiadiazol-1-ylium chloride 2c (67\%), bright red needles, m.p. $150{ }^{\circ} \mathrm{C}$ (decomp. with loss of colour). (Found: C, 32.75; H, 1.76; N, 8.42. $\mathrm{C}_{9} \mathrm{H}_{6} \mathrm{~F}_{3} \mathrm{~N}_{2} \mathrm{~S}_{3} \mathrm{Cl}$ requires C, 32.68; H, 1.82; N, 8.47\%); $v_{\max }(\mathrm{KBr}) / \mathrm{cm}^{-1} 3081,1646,1540,1490,1418,1328,1288,1246,1184,1133,1067$, 1021, 877, 854, 836, 752, 706; $\delta_{\mathrm{H}}\left(\mathrm{SOCl}_{2} / \mathrm{CDCl}_{3}\right) 4.69$ (s, 2H, SCH$), 7.62$ (s, 4H, aromatic H); $\mathrm{m} / z 295\left(\mathrm{M}^{\cdot+}-\mathrm{Cl}\right)$, 234, 192, 159 (100\%). 4-(4'-methylbenzyl)sulfanyl-[1,2,3,5] dithiadiazol-1ylium chloride 2d (55\%), bright red crystals, m.p. $145{ }^{\circ} \mathrm{C}$ (decomp. with loss of colour). (Found: $\mathrm{C}$, 39.12; $\mathrm{H}, 3.18 ; \mathrm{N}, 10.19$. $\mathrm{C}_{9} \mathrm{H}_{9} \mathrm{~N}_{2} \mathrm{~S}_{3} \mathrm{Cl}$ requires $\left.\mathrm{C}, 39.05 ; \mathrm{H}, 3.28 ; \mathrm{N}, 10.12 \%\right)$; $v_{\max }(\mathrm{KBr}) / \mathrm{cm}^{-1}$ 3025, 1647, 1513, 1417, 1318, 1286, 1205, 1183, 1102, 877, 854, 736; $\delta_{\mathrm{H}}$ $\left(\mathrm{SOCl}_{2} / \mathrm{CDCl}_{3}\right) 2.34$ (s, 3H, $\left.\mathrm{CH}_{3}\right), 4.62$ (s, 2H, SCH ), 7.16 (d, 2H, J 7.5 Hz, aromatic H), 7.34 (d, 2H, $J 7.5 \mathrm{~Hz}$, aromatic H); $m / z$ 180, 138, 105 (100\%).

\section{Preparation of $\boldsymbol{S}$-benzyl-iso-thiuronium chlorides 9}

S-benzyl-iso-thiuronium chloride 9a was prepared by the method of Chambers and Watts. ${ }^{15}$ Equimolar amounts of thiourea and benzyl chloride were heated under reflux in ethanol solution. An exothermic reaction took place and after one hour the mixture was cooled and the crystalline product collected. Recrystallisation from ethanol gave the chloride 9a (82\%), m.p. $148{ }^{\circ} \mathrm{C}$ (lit. ${ }^{16}$ m.p. $150{ }^{\circ} \mathrm{C}$ ) which was used without further characterisation.

In a similar manner the following chlorides were prepared from thiourea and the corresponding benzyl chloride. In each case the salt was identified by IR and ${ }^{1} \mathrm{H}$ NMR and, if known, used without further characterisation. S-4-chlorobenzyl-iso-thiuronium chloride 9b (78\%), m.p. 181-2 (lit. ${ }^{17}$ m.p. 177-8 ${ }^{\circ} \mathrm{C}$ ). $v_{\max }(\mathrm{KBr}) / \mathrm{cm}^{-1}$ 3057, 2709, 1655, 1493, 1436, 1093, 1017, 898, 820, 715, 623, 500, 465, 439; $\delta_{\mathrm{H}}\left(\mathrm{CDCl}_{3}\right) 3.9$ (br.s, 4H, $\left.\mathrm{N} H_{2}\right), 4.37$ (s, 2H, SCH$)_{2}$, 7.35 (s, 4H, aromatic H); S-4-trifluoromethylbenzyl-iso-thiuronium chloride 9c (66\%), m.p. 219$220{ }^{\circ} \mathrm{C}$. (Found: C, 39.92; H, 3.69; N, 10.31. $\mathrm{C}_{9} \mathrm{H}_{10} \mathrm{~N}_{2} \mathrm{~F}_{3} \mathrm{SCl}$ requires C, 39.93; H, 3.72; N, 10.35\%); $v_{\max }(\mathrm{KBr}) / \mathrm{cm}^{-1}$ 3213, 3059, 2362, 1652, 1441, 1328, 1178, 1138, 1108, 1065, 1018, 903, 837, 698, 630; $\delta_{\mathrm{H}}\left(\mathrm{CDCl}_{3}\right) 4.1$ (br.s, 4H, $\mathrm{NH}_{2}$ ), 4.59 (s, 2H, SCH $H_{2}, 7.68$ (d, $2 \mathrm{H}, J 8.0 \mathrm{~Hz}$, aromatic H), 7.76 (d, 2H, $J 8.0 \mathrm{~Hz}$, aromatic H); $S$-4-methylbenzyl-iso-thiuronium chloride 9d (91\%), m.p. $173{ }^{\circ} \mathrm{C}$ (lit. ${ }^{18}$ m.p. 104(d) ${ }^{\circ} \mathrm{C}$ ). $v_{\max }(\mathrm{KBr}) / \mathrm{cm}^{-1}$ 3213, 3059, 2362, 1652, 1441, 1328, 
1178, 1138, 1108, 1065, 1018, 903, 837, 698, 630; $\delta_{\mathrm{H}}\left(\mathrm{CDCl}_{3}\right) 2.32$ (s, 3H, $\left.\mathrm{CH}_{3}\right), 3.9$ (br.s, $4 \mathrm{H}$, $\mathrm{NH}_{2}$ ), 4.39 (s, 2H, $\mathrm{SCH}_{2}$ ), 7.13 (d, 2H, $J 8.0 \mathrm{~Hz}$, aromatic $\mathrm{H}$ ), 7.26 (d, $2 \mathrm{H}, J 8.0 \mathrm{~Hz}$, aromatic H).

Reaction of salt $\mathbf{2 b}$ with thiourea. A solution of compound $\mathbf{2 b}$ (143 $\mathrm{mg}$ ) was stirred in very dry, freshly distilled THF $\left(50 \mathrm{~cm}^{3}\right)$ under nitrogen. To this solution was added oven-dried $(16 \mathrm{~h})$ thiourea (38 mg). The solution immediately darkened and a flocculent precipitate was formed. When no further change was observed (15 min), the precipitate was collected and identified as compound $\mathbf{9 b}$ (identical to an authentic sample). The filtrate was then concentrated and chilled to yield a crop of pale yellow crystals (mp $118^{\circ} \mathrm{C}$ ) that was identified as sulfur. Further evaporation gave a brown gummy residue that could not be characterised.

\section{Acknowledgement}

We thank the EPSRC Crystallography Service (Southampton) for collection and interpretation of $\mathrm{X}$-ray data and the EPSRC Mass Spectrometry Service (Swansea) for mass spectra.

\section{References}

1. (a) Ramsden, C. A. Adv. Heterocycl. Chem. 1980, 26, 1. (b) Ramsden, C. A. Tetrahedron 1977, 33, 3203. (c) Ollis, W. D.; Stanforth, S. P.; Ramsden, C. A. Tetrahedron 1985, 41, 2239.

2. (a) Ramsden, C. A. Chem. Soc. Rev. 1994, 23, 111. (b) Ramsden, C. A. J. Heterocycl. Chem. 1999, 36, 1573.

3. (a) Ollis, W. D.; Ramsden, C. A. Adv. Heterocycl. Chem. 1976, 19, 1. (b) Newton, C. G.; Ramsden, C. A. Tetrahedron 1982, 38, 2965.

4. Kushi, Y.; Fernando, Q. J. Am. Chem. Soc. 1970, 92, 1965.

5. Cannon, J. R.; Potts, K. T.; Raston, C. L.; Sierakowski, A. F.; White, A. H. Austral. J. Chem. 1978, 31, 297.

6. Barillier, D. Phosphorus and Sulphur 1980, 8, 79.

7. Alange, G. G.; Banister, A. J.; Bell, B.; Millen, P. W. J. C. S. Perkin Trans 1 1979, 1192.

8. Amin, M.; Rees, C. W. J. C. S. Perkin Trans 1 1989, 2495.

9. Andreasen, O.; Hazell, A. C.; Hazell, R. G. Acta Cryst. 1977, B33, 1109.

10. (a) Apblett, A.; Chivers, T. J. C. S. Chem. Commun. 1989, 96. (b) Chivers, T.; Edelmann, F.; Richardson, J. F.; Smith, N. R. M.; Treu, Jr, O.; Trsic, M. Inorg. Chem. 1986, 25, 2119.

11. Domschke, G.; Walther, C.;Tschöpe P.; Bartl, A. J. prakt. Chem. 1994, 336, 266.

12. Tschöpe, P.; Rademacher, O.; Böttcher. P. Z.-Kristallogr - New Crystal Structures 1998, $213,123$. 
13. Dewar, M. J. S.; Zoebisch, E. G.; Healy, E. F.; Stewart, J. J. P. J. Am. Chem. Soc. 1985, 107, 3902.

14. CCDC 188079 contains the supplementary crystallographic data for this paper. These data can be obtained free of charge via www.ccdc.cam.ac.uk/conts/retrieving.html (or from the CCDC, 12 Union Road, Cambridge CB2 1EZ, UK; fax: +44 1223 336033; e-mail: deposit@ccdc.cam.ac.uk

15. Chambers, E.; Watts, G. W. J. Org. Chem. 1941, 6, 376.

16. Lecker, H.; Heuck, C. Liebigs Ann. 1924, 438, 169.

17. Harvey, R. G.; Jensen, E. V. J. Org. Chem. 1963, $28,470$.

18. Kumar, A.; Tilak, B. D. Ind. J. Chem. 1987, 26B, 599. 